Published in final edited form as:

Curr Opin Pediatr. 2015 April ; 27(2): 193-200. doi:10.1097/MOP.0000000000000195.

\title{
Autosomal dominant polycystic kidney disease in children
}

\author{
Melissa A. Cadnapaphornchai \\ Children's Hospital Colorado, University of Colorado Denver, Aurora, Colorado, USA
}

\begin{abstract}
Purpose of review-Autosomal dominant polycystic kidney disease (ADPKD) is the most common hereditary renal disease, affecting one in 500 individuals. The cardinal manifestation of ADPKD is progressive cystic dilatation of renal tubules with kidney enlargement and progression to end-stage renal disease in approximately half of cases by 60 years of age. Although previously considered a condition of adults, it is clear that children and young adults are subject to the complications of ADPKD.
\end{abstract}

Recent findings-It has been increasingly recognized that interventions early in life are necessary in order to confer the best long-term outcome in this common condition. Therefore, it is imperative for pediatricians to recognize the manifestations and complications of this disease. Until recently ADPKD management focused on general principles of chronic kidney disease. However, several recent clinical trials in children and adults with ADPKD have focused on disease-specific therapies.

Summary-This review will highlight the clinical manifestations, diagnosis, and appropriate management of ADPKD in childhood and will review recent relevant clinical trials in children and adults with this condition.

\section{Keywords}

autosomal dominant polycystic kidney disease; management; pediatric

\section{Introduction}

Autosomal dominant polycystic kidney disease (ADPKD) is the most common hereditary renal disease, affecting approximately one in 500 individuals worldwide [1]. Although historically termed 'adult' polycystic kidney disease, it is clear that important clinical manifestations including progressive structural kidney disease are evident in childhood and even in utero in some cases [2,3]. Cystic kidney disease accounts for nearly 5\% of end-stage renal disease (ESRD) in the United States [1]. Early intervention in childhood, which ameliorates the progression of ADPKD to chronic kidney failure, would be anticipated to have major long-term impact on individual health and medical resources. The purpose of this article is to review the clinical findings, diagnosis, and appropriate management of

Copyright $@ 2015$ Wolters Kluwer Health, Inc. All rights reserved.

Correspondence to Melissa A. Cadnapaphornchai, MD, Kidney Center, Children's Hospital Colorado, 13123 E. 16th Ave, BoxB328, Aurora, CO 80045, USA, Tel: +1 720777 3932, fax: +1 720777 7200, Melissa.Cadnapaphornchai@ ucdenver.edu.

Conflicts of interest: None. 
ADPKD in childhood and to emphasize the importance of early diagnosis and management of this condition.

\section{Clinical Findings}

The cardinal manifestation of ADPKD is bilateral progressive cystic dilation of the renal tubules with eventual compression of normal renal parenchyma, kidney enlargement, and loss of renal function, such that approximately half of affected individuals reach ESRD by 60 years of age [4,5]. Kidney cysts may be evident by prenatal ultrasonography, although more commonly, diffusely enlarged kidneys with variable echogenicity or normal kidneys are observed by current imaging techniques [3,6,7]. Kidney enlargement due to cystic involvement is observed in many affected children, although there is a wide range of severity, even within the same family. ADPKD children demonstrate faster kidney growth by ultrasound than unaffected children, and those with severe kidney enlargement at a young age manifest faster kidney growth than those with mild enlargement or normal kidney size for their age [8]. Children who are diagnosed due to signs or symptoms (e.g., oligohydramnios, hypertension, impaired renal function) before 18 months of age have 'very early onset' (VEO) ADPKD and demonstrate larger kidneys with more cysts when adjusted for age than children diagnosed later in life [9]. Such children are at particular risk for hypertension and early loss of kidney function [3].

Structural cystic kidney disease can be associated with acute or chronic flank, back, or abdominal pain in childhood. Such pain has been attributed both to capsular stretch by growing cysts and to cyst hemorrhage, which can occur spontaneously or with minimal trauma. In some cases, recurrent pain is severe, and chronic pain management is required. However, many children are asymptomatic despite evidence of prior cyst hemorrhage on abdominal imaging.

Hypertension affects 10-35\% of children with ADPKD [10-13] and is particularly common in VEO ADPKD. The strong correlation between hypertension and larger kidneys has been observed in multiple cohorts of ADPKD children [8,14,15,16"]. Whether hypertension or kidney enlargement is the inciting event is not known but it seems likely that each contributes to the other $[17,18]$. The presence of hypertension is an ominous sign and is associated with a decrease in estimated glomerular filtration rate (eGFR) over time [15]. Hypertension in an affected parent is associated with increased frequency and earlier age of onset of hypertension in ADPKD offspring [11]. Ambulatory blood pressure monitoring is critical in the assessment of ADPKD children, as nearly one-third of children show exclusively nocturnal hypertension [12,19-22]. The pathogenesis of hypertension in ADPKD is multifactorial and appears to involve the renin-angiotensin-aldosterone, nitric oxide, and sympathetic nervous systems (reviewed in [18]).

Additional renal manifestations of ADPKD in childhood include micro and gross hematuria and proteinuria. Hematuria can occur with cyst hemorrhage, although most cysts are noncommunicating. Overt proteinuria is associated with more advanced structural kidney disease [8,23]. In contrast to adults with ADPKD [23], we have found no correlation 
between microalbuminuria and either kidney volume or function in children with ADPKD $\left[15,16^{\mathbf{*}}\right]$.

As very extensive structural disease is required before any measurable decrease in eGFR, the vast majority of affected children maintain normal eGFR. However, glomerular hyperfiltration is common [24] and portends risk of progression. Glomerular hyperfiltration ( $24 \mathrm{~h}$ urine creatinine clearance $\geq 140 \mathrm{ml} / \mathrm{min} / 1.73 \mathrm{~m}^{2}$ ) is associated with significantly faster decline in eGFR and higher rate of kidney enlargement over time [25]. Because diminished eGFR is a sign of advanced disease, total kidney volume (TKV) has been utilized as an early marker of disease progression [26-28]. TKV measurement by ultrasound correlates well with MRI in most affected children due to their relatively small kidney size compared with affected adults [29].

Urolithiasis affects children with ADPKD at increased frequency compared with the general population, with urine abnormalities similar to those observed in ADPKD adults (e.g., low urine volume, hypocitraturia). Hepatic, pancreatic, and splenic cysts can occur in childhood ADPKD, most commonly in teenagers. However, such cystic involvement rarely constitutes more than a few small cysts. Intracranial aneurysms (ICA) can occur in children with ADPKD [30,31] but are of such rarity that routine screening is not indicated during childhood.

Cardiovascular disease is a major feature of ADPKD. In addition to hypertension, there is increased frequency of cardiac valve abnormalities in both ADPKD children and adults. The prevalence of mitral valve prolapse is $12 \%$ in ADPKD children as compared with only $3 \%$ in controls [32]. ADPKD children, but not their unaffected siblings, demonstrate a significant correlation between left ventricular mass index (LVMI) and systolic blood pressure [32]. Hypertensive ADPKD children have a significantly higher LVMI than normotensive ADPKD children [15,32]. Interestingly, children with ADPKD and blood pressure in the upper range of normal (75-95th percentile for age, sex, and height) have LVMI similar to that of hypertensive ADPKD children despite significantly smaller TKV[14], suggesting that cardiovascular disease may be an early feature of pediatric ADPKD. Overt left ventricular hypertrophy is uncommon in ADPKD children. Endothelial dysfunction due to disordered nitric oxide and endothelin metabolism occurs in adults with ADPKD [33-35]. Similar studies are ongoing in pediatric ADPKD.

In summary, with the exception of kidney failure and ICA, the clinical manifestations observed in pediatric ADPKD are similar to those seen in affected adults. Attention to these signs and symptoms is therefore indicated during routine follow-up of children with, or at risk of, ADPKD.

\section{Genetics}

ADPKD is caused by mutations in two genes: PKDl (chromosome 16p13.3), which encodes polycystin-1 (PC1), and PKD2 (chromosome 4q21), which encodes polycystin-2 (PC2). Although a third gene has been proposed, none has been identified [36]. Among adult patients referred for nephrology evaluation, $P K D 1$ mutations account for approximately $78 \%$ of cases with the remaining $13 \%$ of cases due to $P K D 2$ mutations and $9 \%$ due to de- 
novo mutations [37-39]. It is estimated, however, that $P K D 2$ mutations, which typically confer a milder course, may account for up to $25 \%$ of mutations in the general population [40]. PC1 is a large integral membrane protein whose structure resembles a receptor or adhesion molecule [41]. PC2 is a six-transmembrane $\mathrm{Ca}^{2+}$-responsive cation channel of the transient receptor potential family $[42,43]$. PC1 and PC2 are thought to interact via their Cterminal tails with the resulting PC complex playing a role in intracellular $\mathrm{Ca}^{2+}$ regulation.

PC1, PC2, and other proteins associated with renal cystic disease have been localized to the primary cilium in the renal tubule and other epithelium. The cilium may function as a flow detector, facilitating calcium influx when flow is present and restricting influx in response to a lack of flow or loss of the PC complex [44]. In this manner, multiple signaling pathways that regulate cell proliferation and fluid secretion, including cyclic adenosine monophosphate (cAMP), are altered in favor of cyst formation [44]. Increasing evidence supports the concept that cysts develop below a specific PC threshold, with the dosage of functional PC correlating with disease severity [45]. Reaching this threshold could be impacted by numerous factors, including the specific somatic mutation; variants in genes including PKD1, PKD2, and others associated with cystic renal disease; stochastic expression differences between cells; and environmental factors such as kidney injury [46,47]. This concept aligns with the 'second-hit' hypothesis of cyst formation [48].

$P K D 1$ is generally associated with more severe disease than $P K D 2$, with earlier age at diagnosis, higher number of kidney cysts, earlier onset of hypertension, and faster progression to ESRD [49,50]. The Consortium for the Radiologic Imaging Study of PKD (CRISP) has demonstrated in adults that cysts within PKD1 and PKD2 kidneys grow at similar rates; however, kidneys with $P K D 1$ mutations enlarge faster than $P K D 2$ kidneys because they contain more cysts [51,52]. Factors associated with early adverse structural and functional outcomes include PKDI mutation (particularly truncating mutation), male sex, early onset of hypertension, early and frequent gross hematuria, three or more pregnancies among affected females, and overt proteinuria [53"']. Wide intrafamilial phenotypic variability exists and might further be explained by hypomorphic alleles or modifier genes [54,55,56"].

\section{Diagnosis}

Renal ultrasound remains the primary means to diagnose ADPKD in childhood. Such studies are readily obtained, relatively inexpensive, and provide no radiation exposure to the child. The at-risk child (i.e., a parent is known to be affected) can be diagnosed with ADPKD when bilateral kidney cysts are present [57]. A normal ultrasound during childhood does not exclude ADPKD [58]. MRI can detect cysts as small as 2mm [29]; however, such sophisticated imaging is not routinely indicated for clinical diagnosis considering the associated expense and potential need for sedation in young children. It is not uncommon for children with ADPKD to be diagnosed incidentally during imaging obtained for other reasons.

Simple renal cysts are unusual in childhood but do occur. However, the presence of multiple 'simple' cysts in the absence of significant chronic medical disease [59] is exceedingly 
unusual. When ADPKD is suspected but there is no apparent family history, parents should be screened with ultrasound. The diagnosis of ADPKD in a parent has important implications both for the parent's health and for the risk of inheritance to other offspring.

Prenatal diagnosis of ADPKD is increasing. Sonographic findings are variable and can be difficult to distinguish from other renal cystic disease in the prenatal period. ADPKD can present with enlarged echogenic kidneys with or without discrete cysts. In contrast to autosomal recessive polycystic kidney disease, increased corticomedullary differentiation may be observed. Fetal renal dysfunction with oligohydramnios is unusual in ADPKD and is more commonly observed with bilateral multicystic dysplastic kidneys or autosomal recessive polycystic kidney disease. Parental screening may help elucidate the diagnosis.

Direct mutation analysis (next-generation or Sanger sequencing) is available commercially ( USD \$3000). Consideration must be given to the psychosocial and financial implications of genetic diagnosis, particularly when the proband is asymptomatic. In the United States, the Genetic Information Nondiscrimination Act of 2008 [60] prohibits genetic discrimination in medical insurance and employment but does not address life or disability insurance. It is important for parents to understand these implications, and formal genetic counseling may be indicated. Definitive disease-associated mutations are only found in 40 $60 \%$ [61], likely due to a sampling phenomenon wherein mutation analysis is only pursued when other clinical data are questionably supportive of the diagnosis. Serial renal ultrasound may prove to be more cost-effective in such situations. In the absence of DNA analysis, the family history of ESRD may be helpful in some cases to predict the mutated gene [62].

\section{Supportive Treatment}

For many years, no disease-specific intervention was available for the treatment of ADPKD. Supportive measures were instituted along the general guidelines for chronic kidney disease, with adaptation as appropriate for affected children. Such supportive treatments are reviewed here.

\section{Diet}

Dietary intake of salt, protein, and calories is reportedly associated with worsening kidney volume and function in adults with ADPKD involved in the CRISP study [63"']; a detailed analysis has not been published. Although dietary protein restriction in an animal model of ADPKD was associated with decreased kidney cyst volume and improved renal function [64], similar effects were not observed in ADPKD adult humans, albeit in the setting of advanced structural and functional disease [65]. Regardless, dietary protein restriction is not advocated in growing children including those with chronic kidney disease [66]; however, excessive protein intake should be avoided with underlying renal disease. To date, no specific diet has been studied in or advocated for children with ADPKD. The Dietary Approaches to Stop Hypertension (DASH) programme encourages a balanced dietary pattern that is rich in fruits, vegetables, and fat-free or low-fat dairy foods and is limited in sodium, sugar-sweetened foods and beverages, red meat, and added fat [67]. It promotes lifelong healthy diet choices and is associated with improved blood pressure, cholesterol concentration, and insulin sensitivity in adolescents with systemic hypertension or diabetes 
mellitus in the general population [68-70]. With rising obesity rates in children and the risk for systemic hypertension and other cardiovascular complications in ADPKD, dietary counseling early in life to establish healthy eating patterns with reasonable salt intake makes sense. Other lifestyle interventions targeting healthy body mass index and routine exercise would be anticipated to improve cardiovascular health in general and also potentially support tolerance of the chronic back and flank pain associated with progressive nephromegaly.

\section{High fluid intake}

Arginine vasopressin (AVP) is believed to play a critical role in kidney cyst fluid accumulation in ADPKD. Therefore, suppression of AVP could be a key factor to modulate kidney cyst growth in this condition. Results from the TEMPO (Tolvaptan Efficacy and Safety in Management of ADPKD and Its Outcomes) study showed that pharmacologic blockade of AVP with tolvaptan reduced the usual increase in TKV and decline in GFR observed over time in affected adults [71,72]. Suppression of AVP by high fluid intake has also been proposed as therapy for ADPKD. In an animal model of ADPKD, short-term high fluid intake ( $\sim 3.5$ times normal) resulted in urine osmolality below $290 \mathrm{mOsm} / \mathrm{kg} \mathrm{H}_{2} \mathrm{O}$ with a $30 \%$ reduction in the kidney-to-body weight ratio [73]. A 2-week pilot study conducted in eight ADPKD adults demonstrated that a water intake of 2.4-31/day is sufficient to maintain urine osmolality below $285 \mathrm{mOsm} / \mathrm{kg} \mathrm{H}_{2} \mathrm{O}$ [74]. Whether this is sufficient to chronically and continuously suppress plasma AVP concentration and associated cyst fluid accumulation is not known [75]. Chronic high fluid intake presents specific difficulties for young children, and any such intervention must be performed under close medical supervision. Certainly high fluid intake may be routinely advised in the setting of PKDassociated urolithiasis.

\section{Avoidance of caffeine}

Caffeine-induced inhibition of phosphodiesterase is known to increase the accumulation of cAMP, with subsequent activation of the extracellular signal-related kinase (ERK) pathway to induce cellular proliferation and transepithelial fluid secretion in ADPKD cystic epithelium [76]. This concept has led to the general recommendation to avoid caffeine intake with underlying ADPKD.

\section{Cardiovascular disease surveillance}

Due to the increased frequency of valvular abnormalities, children with abnormal cardiac examination or symptoms suggestive of mitral valve prolapse or other cardiac valve disease should be referred for echocardiogram. Periodic echocardiographic assessment may be indicated in children and young adults with ADPKD and hypertension [19].

\section{Other management}

ADPKD-associated ICA are rare during childhood (median age at diagnosis 49 years [77]) but are strongly influenced by family history [78]. Based on these findings, we recommend routine screening beginning at 18-21 years of age with a known family history of PKDassociated ICA/hemorrhagic stroke or with no known family history of ADPKD. Even with 
such screening, identified ICAs tend to be small and rarely require surgical intervention. Appropriate evaluation is of course indicated with concerning symptoms regardless of the age of the child.

Urolithiasis and urinary tract infection should be evaluated and treated as for children without ADPKD. Chronic back or flank pain may require consultation with a chronic pain team. Avoidance of aspirin and nonsteroidal anti-inflammatory drugs has been empirically recommended in the setting of recurrent cyst hemorrhage. Contact sports may need to be avoided for those children with recurrent cyst hemorrhage or significant nephromegaly. Hyperlipidemia is an unusual finding in ADPKD [79] but should be treated appropriately.

No guidelines exist regarding serial ultrasonogaphy in the routine clinical management of pediatric ADPKD. Certainly repeat imaging is useful when there is concern for rapidly progressive kidney growth, cyst hemorrhage or infection (both better delineated by computed tomography), or other specific clinical concerns. In the absence of systematic measurement of interval kidney growth relative to somatic growth, serial ultrasound may be of limited utility in everyday practice.

\section{Disease-Specific Treatment}

In recent years, there have been several clinical trials designed to slow progression of kidney and cardiovascular disease in ADPKD. The mechanisms contributing to cyst formation and fluid accumulation are complex, and it seems likely that antagonism of a combination of such pathways will lead to the most profound impact on cyst growth and preservation of renal function.

\section{Control of hypertension/renin-angiotensin blockade}

Blood pressure control is a critical component of all chronic kidney disease management in childhood. The ESCAPE trial found that more aggressive control (blood pressure $<50$ th percentile vs. 50-95th percentile) of chronic hypertension with angiotensin-convertingenzyme inhibition (ACEI) slowed loss of kidney function in children with chronic kidney disease stages $2-4[80]$. With a relatively small sample size, we were unable to demonstrate any effect of the degree of blood pressure control with ACEI on either TKV or kidney function in hypertensive children and young adults with ADPKD in a randomized controlled clinical trial [15]. The recently completed double-blind placebo-controlled HALT-PKD clinical trial compared aggressive vs. standard control of blood pressure with either ACEI or combined ACEI and angiotensin-receptor blockade (ARB) in 558 hypertensive ADPKD participants ages 15-49 years with relatively preserved eGFR[81"]. Aggressive blood pressure control was associated with a statistically but not clinically significant slowing of the annual percentage increase in TKV over time (5.6 vs. $6.6 \%, P=0.006)$ with no differences observed in eGFR between study groups. Combined ACEI/ARB treatment did not alter the rate of increase in TKV or eGFR as compared with ACEI alone. The results of these studies support the conclusion that hypertension in ADPKD signifies advanced disease in childhood. 
In contrast, children and young adults with high normal (75-95th percentile) blood pressure represent a target group for intervention with ACEI. Treatment of such children with ACEI to a goal blood pressure below the 50th percentile has been shown to prevent the decline in eGFR and increase in LVMI, which is observed with a blood pressure target at the 90th percentile [15]. Therefore, special consideration should be given to starting ACEI in this group for potential preservation of renal and cardiac function. Blockade of the reninangioten-sin-aldosterone system with ACEI or ARB remains the preferred treatment for hypertension in pediatric ADPKD. Medication-related hyperkalemia and decreased GFR are rare in pediatric ADPKD [15] as baseline GFR is nearly always normal. The medication risks to the developing fetus should be reviewed as appropriate with patients/families.

\section{Vasopressin $\mathrm{V}_{2}$ receptor antagonism}

Several years ago, Gattone et al. $[82,83]$ demonstrated an impressive decrease in kidney cyst fluid accumulation via blockade of the vasopressin $\mathrm{V}_{2}$ receptor in rat and mouse models of polycystic kidney disease. The multicenter international TEMPO 3:4 study included nearly 1500 adults with ADPKD, eGFR higher than $60 \mathrm{ml} / \mathrm{min}$, and relatively large kidneys (TKV $>750 \mathrm{ml}$ ) who were randomized to receive either tolvaptan or placebo for 3 years [71,72].

All participants were advised to avoid thirst by drinking a glass of water after each urination. Participants in the tolvaptan arm demonstrated slower annual increase in TKV than controls (2.8 vs. $5.5 \%, P<0.001)$ and slower annual decline in renal function $(-2.6$ vs. $-3.8 \mathrm{mg} / \mathrm{ml}, P$ $<0.001$ ) [71]. Suppression of AVP was observed in both groups, likely due to voluntary increased water intake in placebo participants. In 2013, the US Food \& Drug Administration denied the new drug application for tolvaptan as a treatment for ADPKD, citing concern for side effects (including significant liver enzyme elevation in 4.4\%) and the high dropout rate (23 vs. 14\%). Tolvaptan has not yet been systematically studied in the general pediatric or pediatric PKD populations.

\section{Mammalian target of rapamycin inhibition}

The mammalian target of rapamycin (mTOR) pathway plays an important role in cell growth and proliferation, including interaction of the cytoplasmic tail of polycystin 1 with tuberin [84], and appears to be inappropriately activated in some cystlining epithelial cells in human ADPKD patients and mouse models. Rapamycin, an inhibitor of mTOR, was shown to be effective in reducing cystogenesis in mouse models of ADPKD [84,85]. However, efficacy appears to be dependent on appropriate blood levels [85] and on the tubular origin of cyst development (i.e., effective with proximal tubule but not distal nephron or collecting duct origin) $[84,86]$. These findings and the observation that human ADPKD transplant recipients treated with mTOR showed a reduction in native polycystic kidney size [84] led to two clinical trials of mTOR inhibitors in ADPKD adults with relatively large kidneys. Sirolimus treatment had no effect on TKV or kidney function; however, dosage was limited due to adverse effects [87]. Everolimus treatment resulted in a slower rate of increase in TKV but a faster decline in eGFR [88] in participants with advanced kidney disease; again there was a high dropout rate (33\%). These medications have not been formally studied in pediatric ADPKD. However, the risk-benefit ratio of chronic immunosuppressive therapy with frequent side effects currently restricts the potential for mTOR inhibitor treatment of children with ADPKD. 


\section{Statins}

In addition to their effect to lower cholesterol, HMG-CoA reductase inhibitors (statins) enhance renal blood flow and GFR and attenuate vascular inflammation through vascular and glomerular nitric oxide production [89]. In an animal model of ADPKD, lovastatin reduced the severity of structural and functional kidney disease [90]. Short-term (4-week) simvastatin treatment of 10 ADPKD adults with normal blood pressure and cholesterol concentration was shown to improve renal blood flow and GFR [91]. Based on these findings, a 3-year randomized double-blind placebo-controlled phase III clinical trial was conducted to assess the effect of pravastatin treatment on kidney and cardiovascular disease progression in children and young adults ages 8-22 years with ADPKD and normal kidney function [79]. The percentage change in height-corrected TKV adjusted for age, sex, and hypertension status over the 3-year period was significantly decreased with pravastatin $(23 \pm 3$ vs. $31 \pm 3 \%, P=0.02)\left[16^{\prime \prime}\right]$. The medication was well tolerated with no adverse effects on serum liver or muscle enzymes; no participant discontinued the statin due to side effects. These encouraging results support a role for statins to ameliorate structural kidney disease in young patients with ADPKD. Studies are in progress to examine the potential mechanisms of this effect. Further clinical trials are needed to determine the utility and safety of statins in children under 8 years of age, as the theory remains that the earlier the intervention, the more significant the long-term impact. Potential risks to the fetus with statin exposure should be discussed with patients/families as appropriate.

\section{Screening}

Many pediatric nephrologists have advised against routine screening for ADPKD in at-risk children due to the lack of disease-specific treatments for this condition. However, given the recent findings that statins are effective in mitigating progressive structural kidney disease in pediatric ADPKD, and the potential benefits of early ACEI therapy in children as outlined above, it now makes sense that routine screening be offered to children who are potential candidates for such therapies. The potential benefits and risks of screening, including financial and psychosocial implications, need to be discussed with patients/families prior to the institution of routine screening.

\section{Conclusion}

Much of what we know about pediatric ADPKD has been extrapolated from adult data. However, studies in affected children are increasing in size and scope. These studies are essential to understand the pathogenesis of this condition. With the frequency of ADPKD in the general population, we will be seeing more and more affected children as screening is widely adopted. Multicenter interventional trials with well tolerated and promising therapies beginning early in life are critical if we are to alter the natural course of this disease.

\section{Acknowledgments}

None.

Financial support and sponsorship: None. 


\section{References and Recommended Reading}

Papers of particular interest, published within the annual period of review, have been highlighted as:

- of special interest

- of outstanding interest

1. United States Renal Data System. 2014 annual data report:an overview of the epidemiology of kidney disease in the United States. Bethesda: National Institutes of Health, National Institute of Diabetes and Digestive and Kidney Diseases; 2014.

2. Pretorius DH, Lee ME, Manco-Johnson ML, et al. Diagnosis of autosomal dominant polycystic kidney disease in utero and in the young infant. J Ultrasound Med. 1987; 6:249-255. [PubMed: 3295293]

3. MacDermot KD, Saggar-Malik AK, Economides DL, Jeffery S. Prenatal diagnosis of autosomal dominant polycystic kidney disease (PKD1) presenting in utero and prognosis for very early onset disease. J Med Genet. 1998; 35:13-16. [PubMed: 9475088]

4. Gabow PA. Autosomal dominant polycystic kidney disease. N Engl J Med. 1993; 329:332-342. [PubMed: 8321262]

5. Ecder, T.; Fick-Brosnahan, G.; Schrier, RW. Polycystic kidney disease. In: Schrier, RW., editor. Diseases of the kidney and urinary tract. 8th. Philadelphia: Lippincott Williams \& Wilkins; 2007. p. 502-539.

6. Zerres K, Hansmann M, Knopfle G, Stephan M. Prenatal diagnosis of genetically determined early manifestation of autosomal dominant polycystic kidney disease? Hum Genet. 1985; 71:368-369. [PubMed: 3908289]

7. Ceccherini I, Lituania M, Cordone MS, et al. Autosomal dominant polycystic kidney disease: prenatal diagnosis by DNA analysis and sonography at 14 weeks. Prenat Diagn. 1989; 9:751-758. [PubMed: 2575745]

8. Fick-Brosnahan GM, Tran ZV, Johnson AM, et al. Progression of autosomal-dominant polycystic kidney disease in children. Kidney Int. 2001; 59:1654-1662. [PubMed: 11318935]

9. Shamshirsaz A, Bekheirnia RM, Kamgar M, et al. Autosomal-dominant poly-cystic kidney disease in infancy and childhood: progression and outcome. Kidney Int. 2005; 68:2218-2224. [PubMed: 16221221]

10. Sedman A, Bell P, Manco-Johnson M, et al. Autosomal dominant polycystic kidney disease in childhood: a longitudinal study. Kidney Int. 1987; 31:1000-1005. [PubMed: 3295357]

11. Schrier RW, Johnson AM, McFann K, Chapman AB. The role of parental hypertension in the frequency and age of diagnosis of hypertension in offspring with autosomal-dominant polycystic kidney disease. Kidney Int. 2003; 64:1792-1799. [PubMed: 14531813]

12. Seeman T, Dusek J, Vondrichova H, et al. Ambulatory blood pressure correlates with renal volume and number of renal cysts in children with autosomal dominant polycystic kidney disease. Blood Press Monit. 2003; 8:107-110. [PubMed: 12900587]

13. Fick GM, Duley IT, Johnson AM, et al. The spectrum of autosomal dominant polycystic kidney disease in children. J Am Soc Nephrol. 1994; 4:1654-1660. [PubMed: 8011974]

14. Cadnapaphornchai MA, McFann K, Strain JD, et al. Increased left ventricular mass in children with autosomal dominant polycystic kidney disease and borderline hypertension. Kidney Int. 2008; 74:1192-1196. [PubMed: 18716604]

15. Cadnapaphornchai MA, McFann K, Strain JD, et al. Prospective change in renal volume and function in children with ADPKD. Clin J Am Soc Nephrol. 2009; 4:820-829. [PubMed: 19346430]

16-". Cadnapaphornchai MA, George DM, McFann K, et al. Effect of pravastatin on total kidney volume, left ventricular mass index, and microalbuminuria in pediatric autosomal dominant polycystic kidney disease. Clin J Am Soc Nephrol. 2014; 9:889-896. This is the first clinical trial to show the efficacy of a readily available and generally well-tolerated medication (pravastatin) 
to slow the progression of structural kidney disease in children and young adults with ADPKD. [PubMed: 24721893]

17. Schrier RW. Renal volume, renin-angiotensin-aldosterone system, hypertension, and left ventricular hypertrophy in patients with autosomal dominant polycystic kidney disease. J Am Soc Nephrol. 2009; 20:1888-1893. [PubMed: 19696226]

18. Cadnapaphornchai MA. Hypertension in children with autosomal dominant polycystic kidney disease (ADPKD). Curr Hypertens Rev. 2013; 9:21-26. [PubMed: 23971640]

19. National High Blood Pressure Education Program Working Group on High Blood Pressure in Children and Adolescents. The fourth report on the diagnosis, evaluation, and treatment of high blood pressure in children and adolescents. Pediatrics. 2004; 114:555-576. [PubMed: 15286277]

20. Flynn JT. Ambulatory blood pressure monitoring in children: imperfect yet essential. Pediatr Nephrol. 2011; 26:2089-2094. [PubMed: 21866381]

21. Flynn JT, Urbina EM. Pediatric ambulatory blood pressure monitoring: indications and interpretations. J Clin Hypertens (Greenwich). 2012; 14:372-382. [PubMed: 22672091]

22. Chapman AB, Stepniakowski K, Rahbari-Oskoui F. Hypertension in autosomal dominant polycystic kidney disease. Adv Chronic Kidney Dis. 2010; 17:153-163. [PubMed: 20219618]

23. Chapman AB, Johnson AM, Gabow PA, Schrier RW. Overt proteinuria and microalbuminuria in autosomal-dominant polycystic kidney disease. J Am Soc Nephrol. 1994; 5:1349-1354. [PubMed: 7894001]

24. Wong H, Vivian L, Weiler G, Filler G. Patients with autosomal dominant polycystic kidney disease hyperfiltrate early in their disease. Am J Kidney Dis. 2004; 43:624-628. [PubMed: 15042539]

25. Helal I, Reed B, McFann K, et al. Glomerular hyperfiltration and renal progression in children with autosomal dominant polycystic kidney disease. Clin J Am Soc Nephrol. 2011; 6:2439-2443. [PubMed: 21903987]

26. Chapman AB, Guay-Woodford LM, Grantham JJ, et al. Renal structure in early autosomaldominant polycystic kidney disease (ADPKD): the Consortium for Radiologic Imaging Studies of Polycystic Kidney Disease (CRISP) cohort. Kidney Int. 2003; 64:1035-1045. [PubMed: 12911554]

27. Bae KT, Grantham JJ. Imaging for the prognosis of autosomal dominant polycystic kidney disease. Nat Rev Nephrol. 2010; 6:96-106. [PubMed: 20111050]

28. Chapman AB, Bost JE, Torres VE, et al. Kidney volume and functional outcomes in autosomal dominant polycystic kidney disease. Clin J Am Soc Nephrol. 2012; 7:479-486. [PubMed: 22344503]

29. Cadnapaphornchai MA, Masoumi A, Strain JD, et al. Magnetic resonance imaging of kidney and cyst volume in children with ADPKD. Clin J Am Soc Nephrol. 2010; 6:369-376. [PubMed: 21115621]

30. Kubo S, Nakajima M, Fukuda K, et al. A 4-year-old girl with autosomal dominant polycystic kidney disease complicated by a ruptured intracranial aneurysm. Eur J Pediatr. 2004; 163:675677. [PubMed: 15322866]

31. De BR, Lasjaunias P, Rodesch G, Alvarez H. Endovascular treatment of a ruptured intracranial arterial aneurysm in a 12-year-old child with recessive polycystic kidney disease. Interv Neuroradiol. 1997; 3:333-336. [PubMed: 20678366]

32. Ivy DD, Shaffer EM, Johnson AM, et al. Cardiovascular abnormalities in children with autosomal dominant polycystic kidney disease. J Am Soc Nephrol. 1995; 5:2032-2036. [PubMed: 7579051]

33. Wang D, Iversen J, Wilcox CS, Strandgaard S. Endothelial dysfunction and reduced nitric oxide in resistance arteries in autosomal-dominant polycystic kidney disease. Kidney Int. 2003; 64:13811388. [PubMed: 12969157]

34. Alisir S, Turkmen K, Alpay N, et al. Improvement of coronary flow velocity reserve with telmisartan in patients with autosomal-dominant polycystic kidney disease. South Med J. 2010; 103:409-413. [PubMed: 20375940]

35. Klawitter J, Reed-Gitomer BY, McFann K, et al. Endothelial dysfunction and oxidative stress in polycystic kidney disease. Am J Physiol Renal Physiol. 2014; 307:F1198-F1206. [PubMed: 25234311] 
36. Paul BM, Consugar MB, Ryan LM, et al. Evidence of a third ADPKD locus is not supported by reanalysis of designated PKD3 families. Kidney Int. 2014; 85:383-392. [PubMed: 23760289]

37. Rossetti S, Consugar MB, Chapman AB, et al. Comprehensive molecular diagnostics in autosomal dominant polycystic kidney disease. J Am Soc Nephrol. 2007; 18:2143-2160. [PubMed: 17582161]

38. Audrezet MP, Cornec-Le GE, Chen JM, et al. Autosomal dominant polycystic kidney disease: comprehensive mutation analysis of PKD1 and PKD2 in 700 unrelated patients. Hum Mutat. 2012; 33:1239-1250. [PubMed: 22508176]

39. Reed B, McFann K, Kimberling WJ, et al. Presence of de novo mutations in autosomal dominant polycystic kidney disease patients without family history. Am J Kidney Dis. 2008; 52:1042-1050. [PubMed: 18640754]

40. Dicks E, Ravani P, Langman D, et al. Incident renal events and risk factors in autosomal dominant polycystic kidney disease: a population and family-based cohort followed for 22 years. Clin J Am Soc Nephrol. 2006; 1:710-717. [PubMed: 17699277]

41. Sandford R, Sgotto B, Aparicio S, et al. Comparative analysis of the polycystic kidney disease 1 (PKD1) gene reveals an integral membrane glycoprotein with multiple evolutionary conserved domains. Hum Mol Genet. 1997; 6:1483-1489. [PubMed: 9285785]

42. Cai Y, Maeda Y, Cedzich A, et al. Identification and characterization of poly-cystin-2, the PKD2 gene product. J Biol Chem. 1999; 274:28557-28565. [PubMed: 10497221]

43. Hanaoka K, Qian F, Boletta A, et al. Co-assembly of polycystin-1 and -2 produces unique cationpermeable currents. Nature. 2000; 408:990-994. [PubMed: 11140688]

44. Nauli SM, Alenghat FJ, Luo Y, et al. Polycystins 1 and 2 mediate mechano-sensation in the primary cilium of kidney cells. Nat Genet. 2003; 33:129-137. [PubMed: 12514735]

45. Ma M, Tian X, Igarashi P, et al. Loss of cilia suppresses cyst growth in genetic models of autosomal dominant polycystic kidney disease. Nat Genet. 2013; 45:1004-1012. [PubMed: 23892607]

46. Piontek K, Menezes LF, Garcia-Gonzalez MA, et al. A critical developmental switch defines the kinetics of kidney cyst formation after loss of Pkd1. Nat Med. 2007; 13:1490-1495. [PubMed: 17965720]

47. Takakura A, Contrino L, Zhou X, et al. Renal injury is a third hit promoting rapid development of adult polycystic kidney disease. Hum Mol Genet. 2009; 18:2523-2531. [PubMed: 19342421]

48. Wu G, D'Agati V, Cai Y, et al. Somatic inactivation of Pkd2 results in polycystic kidney disease. Cell. 1998; 93:177-188. [PubMed: 9568711]

49. Cornec-Le GE, Audrezet MP, Chen JM, et al. Type of PKD1 mutation influences renal outcome in ADPKD. J Am Soc Nephrol. 2013; 24:1006-1013. [PubMed: 23431072]

50. Fencl F, Janda J, Blahova K, et al. Genotype-phenotype correlation in children with autosomal dominant polycystic kidney disease. Pediatr Nephrol. 2009; 24:983-989. [PubMed: 19194729]

51. Grantham JJ, Torres VE, Chapman AB, et al. Volume progression in polycystic kidney disease. N Engl J Med. 2006; 354:2122-2130. [PubMed: 16707749]

52. Harris PC, Bae KT, Rossetti S, et al. Cyst number but not the rate of cystic growth is associated with the mutated gene in autosomal dominant polycystic kidney disease. J Am Soc Nephrol. 2006; 17:3013-3019. [PubMed: 17035604]

53-.. Schrier RW, Brosnahan G, Cadnapaphornchai MA, et al. Predictors of autosomal dominant polycystic kidney disease progression. J Am Soc Ne-phrol. 2014; 25:2399-2418. A comprehensive review of the medical literature that discusses factors predictive of a high risk of disease progression in children and adults with ADPKD.

54. Reiterova J, Stekrova J, Merta M, et al. Autosomal dominant polycystic kidney disease in a family with mosaicism and hypomorphic allele. BMC Nephrol. 2013; 14:59. [PubMed: 23496908]

55. Pei Y, Lan Z, Wang K, et al. A missense mutation in PKD1 attenuates the severity of renal disease. Kidney Int. 2012; 81:412-417. [PubMed: 22031115]

56-. Gall EC, Audrezet MP, Meur YL, et al. Genetics and pathogenesis of autosomal dominant polycystic kidney disease: twenty years on. Hum Mutat. 2014; 35:1393-1406. An excellent review of the current understanding of the genetics of ADPKD. [PubMed: 25263802] 
57. Reed B, Nobakht E, Dadgar S, et al. Renal ultrasonographic evaluation in children at risk of autosomal dominant polycystic kidney disease. Am J Kidney Dis. 2010; 56:50-56. [PubMed: 20452711]

58. Pei Y, Obaji J, Dupuis A, et al. Unified criteria for ultrasonographic diagnosis of ADPKD. J Am Soc Nephrol. 2009; 20:205-212. [PubMed: 18945943]

59. Al-Said J, Brumback MA, Moghazi S, et al. Reduced renal function in patients with simple renal cysts. Kidney Int. 2004; 65:2303-2308. [PubMed: 15149344]

60. Berkelhamer JE. Press statement on passage of the Genetic Information Nondiscrimination Act. Clin Pediatr (Phila). 2007; 46:479. [PubMed: 17579098]

61. Pei Y, Watnick T. Diagnosis and screening of autosomal dominant polycystic kidney disease. Adv Chronic Kidney Dis. 2010; 17:140-152. [PubMed: 20219617]

62. Barua M, Cil O, Paterson AD, et al. Family history of renal disease severity predicts the mutated gene in ADPKD. J Am Soc Nephrol. 2009; 20:1833-1838. [PubMed: 19443633]

63-. Grantham JJ. Rationale for early treatment of polycystic kidney disease. Pediatr Nephrol. 2014 [Epub ahead of print] A concise review outlining the importance of early intervention in ADPKD. 10.1007/s00467-014-2882-8

64. Ogborn MR, Sareen S. Amelioration of polycystic kidney disease by modification of dietary protein intake in the rat. J Am Soc Nephrol. 1995; 6:1649-1654. [PubMed: 8749693]

65. Klahr S, Breyer JA, Beck GJ, et al. Dietary protein restriction, blood pressure control, and the progression of polycystic kidney disease. Modification of Diet in Renal Disease Study Group. J Am Soc Nephrol. 1995; 5:2037-2047. [PubMed: 7579052]

66. Chaturvedi S, Jones C. Protein restriction for children with chronic renal failure. Cochrane Database Syst Rev. 2007:CD006863. [PubMed: 17943919]

67. Appel LJ, Moore TJ, Obarzanek E, et al. A clinical trial of the effects of dietary patterns on blood pressure. DASH Collaborative Research Group. N Engl J Med. 1997; 336:1117-1124. [PubMed: 9099655]

68. Couch SC, Saelens BE, Levin L, et al. The efficacy of a clinic-based behavioral nutrition intervention emphasizing a DASH-type diet for adolescents with elevated blood pressure. J Pediatr. 2008; 152:494-501. [PubMed: 18346503]

69. Moore LL, Bradlee ML, Singer MR, et al. Dietary Approaches to Stop Hypertension (DASH) eating pattern and risk of elevated blood pressure in adolescent girls. Br J Nutr. 2012; 108:16781685. [PubMed: 22243687]

70. Saneei P, Hashemipour M, Kelishadi R, et al. Effects of recommendations to follow the Dietary Approaches to Stop Hypertension (DASH) diet v. usual dietary advice on childhood metabolic syndrome: a randomised cross-over clinical trial. Br J Nutr. 2013; 110:2250-2259. [PubMed: 23773316]

71. Torres VE, Chapman AB, Devuyst O, et al. Tolvaptan in patients with autosomal dominant polycystic kidney disease. N Engl J Med. 2012; 367:2407-2418. [PubMed: 23121377]

72. Torres VE, Meijer E, Bae KT, et al. Rationale and design of the TEMPO (Tolvaptan Efficacy and Safety in Management of Autosomal Dominant Polycystic Kidney Disease and its Outcomes) 3-4 Study. Am J Kidney Dis. 2011; 57:692-699. [PubMed: 21333426]

73. Nagao S, Nishii K, Katsuyama M, et al. Increased water intake decreases progression of polycystic kidney disease in the PCK rat. J Am Soc Nephrol. 2006; 17:2220-2227. [PubMed: 16807403]

74. Wang CJ, Creed C, Winklhofer FT, Grantham JJ. Water prescription in autosomal dominant polycystic kidney disease: a pilot study. Clin J Am Soc Nephrol. 2011; 6:192-197. [PubMed: 20876670]

75. Barash I, Ponda MP, Goldfarb DS, Skolnik EY. A pilot clinical study to evaluate changes in urine osmolality and urine cAMP in response to acute and chronic water loading in autosomal dominant polycystic kidney disease. Clin J Am Soc Nephrol. 2010; 5:693-697. [PubMed: 20167686]

76. Belibi FA, Wallace DP, Yamaguchi T, et al. The effect of caffeine on renal epithelial cells from patients with autosomal dominant polycystic kidney disease. J Am Soc Nephrol. 2002; 13:27232729. [PubMed: 12397042] 
77. Irazabal MV, Huston J III, Kubly V, et al. Extended follow-up of unruptured intracranial aneurysms detected by presymptomatic screening in patients with autosomal dominant polycystic kidney disease. Clin J Am Soc Nephrol. 2011; 6:1274-1285. [PubMed: 21551026]

78. Xu HW, Yu SQ, Mei CL, Li MH. Screening for intracranial aneurysm in 355 patients with autosomal-dominant polycystic kidney disease. Stroke. 2011; 42:204-206. [PubMed: 21164130]

79. Cadnapaphornchai MA, George DM, Masoumi A, et al. Effect of statin therapy on disease progression in pediatric ADPKD: design and baseline characteristics of participants. Contemp Clin Trials. 2011; 32:437-445. [PubMed: 21266204]

80. Wuhl E, Trivelli A, Picca S, et al. Strict blood-pressure control and progression of renal failure in children. N Engl J Med. 2009; 361:1639-1650. [PubMed: 19846849]

81-. Schrier RW, Abebe KZ, Perrone RD, et al. Blood pressure in early autosomal dominant polycystic kidney disease. N Engl J Med. 2014; 371:2255-2266. Results of the largest multicenter clinical trial examining the degree of blood pressure control and renin-angiotensin-aldosterone blockade in adults with ADPKD and preserved renal function. [PubMed: 25399733]

82. Torres VE, Wang X, Qian Q, et al. Effective treatment of an orthologous model of autosomal dominant polycystic kidney disease. Nat Med. 2004; 10:363-364. [PubMed: 14991049]

83. Wang X, Gattone V, Harris PC, Torres VE. Effectiveness of vasopressin V2 receptor antagonists OPC-31260 and OPC-41061 on polycystic kidney disease development in the PCK rat. J Am Soc Nephrol. 2005; 16:846-851. [PubMed: 15728778]

84. Shillingford JM, Murcia NS, Larson CH, et al. The mTOR pathway is regulated by polycystin-1, and its inhibition reverses renal cystogenesis in polycystic kidney disease. Proc Natl Acad Sci U S A. 2006; 103:5466-5471. [PubMed: 16567633]

85. Zafar I, Ravichandran K, Belibi FA, et al. Sirolimus attenuates disease progression in an orthologous mouse model of human autosomal dominant polycystic kidney disease. Kidney Int. 2010; 78:754-761. [PubMed: 20686448]

86. Renken C, Fischer DC, Kundt G, et al. Inhibition of mTOR with sirolimus does not attenuate progression of liver and kidney disease in PCK rats. Nephrol Dial Transplant. 2011; 26:92-100. [PubMed: 20615907]

87. Serra AL, Poster D, Kistler AD, et al. Sirolimus and kidney growth in autosomal dominant polycystic kidney disease. N Engl J Med. 2010; 363:820-829. [PubMed: 20581391]

88. Walz G, Budde K, Mannaa M, et al. Everolimus in patients with autosomal dominant polycystic kidney disease. N Engl J Med. 2010; 363:830-840. [PubMed: 20581392]

89. McFarlane SI, Muniyappa R, Francisco R, Sowers JR. Pleiotropic effects of statins: lipid reduction and beyond. J Clin Endocrinol Metab. 2002; 87:1451-1458. [PubMed: 11932263]

90. Zafar I, Tao Y, Falk S, et al. Effect of statin and angiotensin-converting enzyme inhibition on structural and hemodynamic alterations in autosomal dominant polycystic kidney disease model. Am J Physiol Renal Physiol. 2007; 293:F854-F859. [PubMed: 17581927]

91. van Dijk MA, Kamper AM, van Veen S, et al. Effect of simvastatin on renal function in autosomal dominant polycystic kidney disease. Nephrol Dial Transplant. 2001; 16:2152-2157. [PubMed: 11682660] 


\section{Key Points}

- With the exception of renal insufficiency and intracranial aneurysms, many of the typical findings in adults with ADPKD also affect children with ADPKD. It is important for providers to be aware of these manifestations when caring for children with, or at risk of, ADPKD.

- Further research is needed into the benefits of a balanced low-salt diet and routine exercise, relatively benign interventions, on the management of childhood ADPKD.

- Pravastatin appears to be a well-tolerated and effective agent to slow the progression of structural kidney disease in older children and young adults with ADPKD.

- With the potential therapeutic benefits of angiotensin-converting-enzyme inhibition and statins, we should anticipate more routine screening of at-risk children and therefore increased diagnosis of ADPKD in the pediatric population. 